Review Article

\section{Parabens: The love - hate molecule}

\author{
PD Gupta* ${ }^{1 *}$ and K Pushkala²
}

${ }^{1}$ Former, Director Grade Scientist, Centre for Cellular and Molecular Biology, Hyderabad, India

${ }^{2}$ Former, Associate Professor, S.D.N.B. Vaishnav College for Women, Chromepet, Chennai, India

Parabens are the esters of para-hydroxybenzoic acid [1], mimicking oestrogen, the hormone which makes a woman a woman; women love it and men hate it. However, with an excess use of this compound, even women can develop cancers of oestrogen responsive organs. Michelle ScottLynch says 'Parabens are first introduced in the 1950s as a type of preservative which prolong shelf life in many health and beauty products by preventing the growth of mould and bacteria within them. Common parabens include methylparaben (E number E218), ethylparaben (E214), propylparaben (E216), butylparaben and heptylparaben (E209). Less common parabens include isobutylparaben, isopropylparaben, benzylparaben and their sodium salts; all of them are synthetic chemicals. It is well known fact that too much oestrogen can trigger an increase in breast cell division and growth of tumours. Because parabens are found in a wide variety of foods, beverages, pharmaceuticals, cosmetics and other personal care products, parabens exposure occurs when these products are swallowed or absorbed through the skin, according to the Centres for Disease Control and Prevention (CDC).

With the rates of some types of cancer increasing, additives in food and personal products are increasingly under scrutiny. A scientific review of cosmetics and their cancer risks published in 2018 in the JNCI Cancer Spectrum journal concluded that there is no evidence to suggest that using paraben-containing products leads to an increased risk of cancer. Ironically, while parabens preserve the shelf life of the product whereas may be taking years off product user's lives $[2,3]$.

\section{Where are parabens hiding?}

Cosmetics such as Tooth pastes. Lotions, Shower Gels, Vaginal Lubricants, Perfumes, Indoor Dust, Suntan Lotion, Makeup Foundation, Lipsticks, Makeup Powder, Eye Liner, Eye Shadow, Shampoo, Conditioners, Bar Soap, Liquid Soap, and Nail Polish all contain parabens.

In addition, to use as preservative in cosmetics, parabens can also be found in baked foods, beverages, syrups, jellies, jams to keep them fresh. According to the CDC's National Biomonitoring Programsome drugs also contain parabens.

\author{
More Information \\ *Address for Correspondence: PD Gupta, \\ Former, Director Grade Scientist, Centre for \\ Cellular and Molecular Biology, Hyderabad, India \\ Tel: +91 8072891356; \\ Email: pdg2000@hotmail.com \\ Submitted: 01 March 2020 \\ Approved: 30 April 2020 \\ Published: 02 May 2020 \\ How to cite this article: Gupta PD, Pushkala \\ K. Parabens: The love - hate molecule. Clin J \\ Obstet Gynecol. 2020; 3: 037-038 \\ DOI: 10.29328/journal.cjog.1001047 \\ Copyright: @ 2020 Gupta PD, et al. This is an \\ open access article distributed under the Creative \\ Commons Attribution License, which permits \\ unrestricted use, distribution, and reproduction \\ in any medium, provided the original work is \\ properly cited. \\ (D) Check for updates \\ (1) OPEN ACCESS
}

\section{Pregnancy and parabens}

For pregnant women, in particular, parabens are a serious cause for concern when it comes to makeup and skin lotions. Parabens can impact all stages of pregnancy; from conception to child birth. Both human and animal studies suggested that these chemicals may interfere with a woman's ability to become pregnant. Women, who are with higher paraben levels have lower antral follicle counts [4], which are a measure of egg supply and indicate fertility. Recent research has shown that exposure to these chemicals during pregnancy may up a baby's risk of increased weight gain in infancy, which has been linked to obesity in adulthood [5], however, the U.S. Food and Drug Administration (FDA) says studies have not yet definitively proven that parabens harm your or your baby's health but it may be the case where FDA acted in the case of "Coca cola' [6].

Pregnant mothers with the highest paraben levels had a greater chance of having a preterm birth and that babies conceived to these mothers had decreased gestational age at birth, lower birth weight, and decreased body length [7]. Another study found that women with higher urinary levels of methylparaben and ethylparaben were likely to have less children compared with women with lower levels [8].

Many studies in rodents sounded the alarm that parabens are a cause for concern. For example, one study in rats found that oral exposure to methylparaben during pregnancy increased litter size, but also increased mortality of the offspring from postnatal day seven onwards. This was probably 
due to abnormalities in the mammary glands of the mothers [9]. Other researchers observed that butylparaben exposure to pregnant rats was harmful to the reproductive system of male offspring $[10,11]$. These offspring had higher oestrogen levels. In animal studies, maternal exposure to parabens also damages testicular structure and function in the male offspring, causing abnormalities in their sperm when they become adults [10]. A similar effect occurred when 3-week old rats were exposed to butylparaben. The sperm count in these animals dropped by more than $58 \%$ compared with rats not given butylparaben [11]. The daily sperm production in the test is also significantly declined. And serum testosterone levels dropped as well.

The harm that parabens may cause to infants extends beyond reproductive problems. Butylparaben given to pregnant animals orally and subcutaneously was associated with problems with social interactions, learning, and memory in the offspring [12]. The problems were similar to those seen when the researchers induced autism in rats. In another study, isobutylparaben given to pregnant rats subcutaneously led to anxiety and reduced learning performance in mature male offspring [13]. Cosmetic and beauty Ingredients such as the vitamin A derivatives (Retin-A, Retinol and Retinyl Palmitate) can lead to dangerous birth defects. Chemicals such as, Tazorac, Accutane, Benzoyl Peroxide, Salicylic acids. Essential Oils. Hydroquinone. ..Aluminum chloride. ..Formaldehyde. Sunscreen Chemical should be avoided during pregnancy

As a result, parabens may contribute to fertility problems and an increased risk of breast cancer. Parabens have also been known to disrupt baby growth during foetal gestation and the first years of life. When it comes to paraben dangers, experts are still trying to figure out exactly how parabens are absorbed into the body. More research is needed to determine what the exact effects of parabens are on moms and babies and how those effects can be reduced. It's not known yet whether parabens have more of an effect on the babies and children than they do on adults. However, it is known that young babies are more likely to absorb parabens through their skin than older children and adults are. This is true of any chemicals, not just parabens [14].

\section{References}

1. Freese E, Sheu CW, Galliers E. Function of lipophilic acids as antimicrobial food additives. Nature. 1973; 241: 321-325.

PubMed: https://www.ncbi.nlm.nih.gov/pubmed/4633553
2. Błędzka ID, Gromadzińska J, Wąsowicz W. Parabens. From environmental studies to human health. Environ Internl. 2014; 67: 27-42. PubMed: https://www.ncbi.nlm.nih.gov/pubmed/24657492

3. Chen J, Ahn KC, Gee NA, Gee SJ, Hammock BD, et al. Antiandrogenic properties of parabens and other phenolic containing small molecules in personal care products. Toxicol Applied pharmacol. 2007; 221; 278-284.

PubMed: https://www.ncbi.nlm.nih.gov/pubmed/17481686

4. Karwacka A, Zamkowska D, Radwan M, Jurewicz J. Exposure to modern, widespread environmental endocrine disrupting chemicals and their effect on the reproductive potential of women: an overview of current epidemiological evidence. Hum Fertil (Camb). 2019; 31:1-25. PubMed: https://www.ncbi.nlm.nih.gov/pubmed/28758506

5. Huixia Li, Zheng J, Wang H, Huang G, Huang Q, et al. Maternal cosmetics use during pregnancy and risks of adverse outcomes: a prospective cohort study. Sci Rep. 2019; 9: 8030.

6. White M, Gates O. Decisions of Courts in Cases Under the Federal Food and Drugs Act, Washington DC. GPO, 1934; 1204.

7. Geer LA, Pycke BFG, Waxenbaum J, Sherer DM, Abulafia O, et al. Association of birth outcomes with fetal exposure to parabens, triclosan and triclocarban in an immigrant population in Brooklyn, New York. J Hazardous Materials. 2017; 323: 177-183.

PubMed: https://www.ncbi.nlm.nih.gov/pubmed/27156397

8. Smarr MM, Sundaram R, Honda M, Kannan K, Buck Louis GM. Urinary concentrations of parabens and other antimicrobial chemicals and their association with couples' fecundity. Environ Health Perspect. 2016; 124: 730-736.

PubMed: https://www.ncbi.nlm.nih.gov/pubmed/27286252

9. Manservisi F, Gopalakrishnan K, Tibaldi E, Hysi A, lezzi M, et al. Effect of maternal exposure to endocrine disrupting chemicals on reproduction and mammary gland development in female SpragueDawley rats. Reproductive Toxicology. 2015; 54: 110-119. PubMed: https://www.ncbi.nlm.nih.gov/pubmed/25554385

10. Guerra MT, Sanabria M, Leite GA, Borges CS, Cucielo MS, et al. Maternal exposure to butyl paraben impairs testicular structure and sperm quality on male rats. Environ Toxicol. 2017; 32:1273-1289. PubMed: https://www.ncbi.nlm.nih.gov/pubmed/27444704

11. Oishi S. Effects of butylparaben on the male reproductive system in rats. Toxicol Ind Health. 2001; 17: 31-39.

PubMed: https://www.ncbi.nlm.nih.gov/pubmed/12004923

12. Ali EH, Elgoly AH. Combined prenatal and postnatal butylparaben exposure produces autism-like symptoms in offspring: comparison with valproic acid autistic model. Pharmacol Biochem Behav. 2013; 111: 102-110.

PubMed: https://www.ncbi.nlm.nih.gov/pubmed/24036472

13. Kawaguchi M, Irie K, Morohoshi K, Watanabe G, Taya K, et al. Maternal isobutyl-paraben exposure alters anxiety and passive avoidance test performance in adult male rats. Neurosci Res. 2009; 65: 136-140. PubMed: https://www.ncbi.nlm.nih.gov/pubmed/19560493

14. Gupta PD, Pushkala K. Increasing woman's health concern due to xenoestrogens and parabens: a review. J Cell Tissue Res. 2019; 19 6829-6832. 